\section{Buceando en la pelvis}

\section{Pelvis Diving}

\author{
María Paula Seguí ${ }^{1} \quad$ Elber Eduardo Inclán ${ }^{1}$ \\ ${ }^{1}$ Hospital San Martín, La Plata, Buenos Aires, Argentina \\ Rev Argent Radiol 2019;83:44.
}

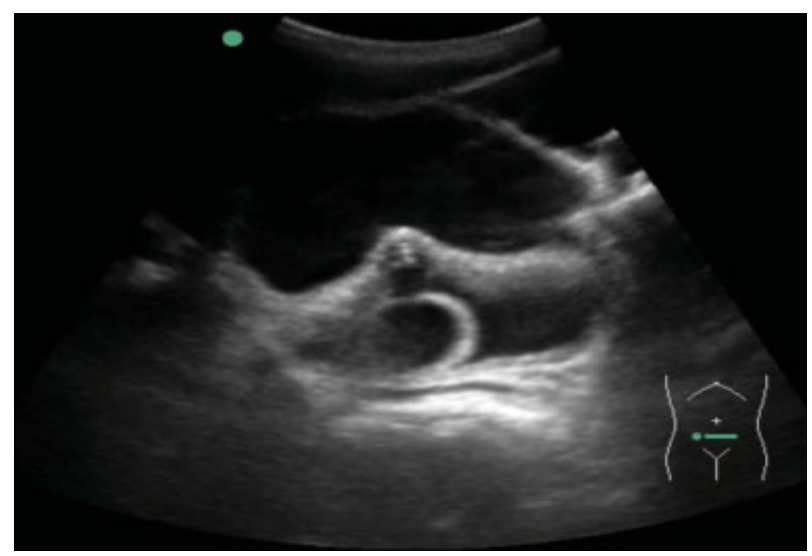

Fig. 1 Corte transversal a nivel del fondo de saco recto-vesical. Se visualiza balón de sonda intravesical y abundante cantidad de líquido libre.

La ecografía FAST (focused abdominal sonography for trauma) tiene como principal objetivo la búsqueda de líquido libre en aquellos pacientes que han sufrido un traumatismo abdominal cerrado, con el fin de determinar la necesidad de una intervención quirúrgica urgente.

Se presenta a continuación un paciente joven, con el antecedente de un traumatismo abdominal, al cual se le
Address for correspondence María Paula Seguí, Hospital San Martín, La Plata, Buenos Aires, Argentina

(e-mail: mpsegui_89@hotmail.com).

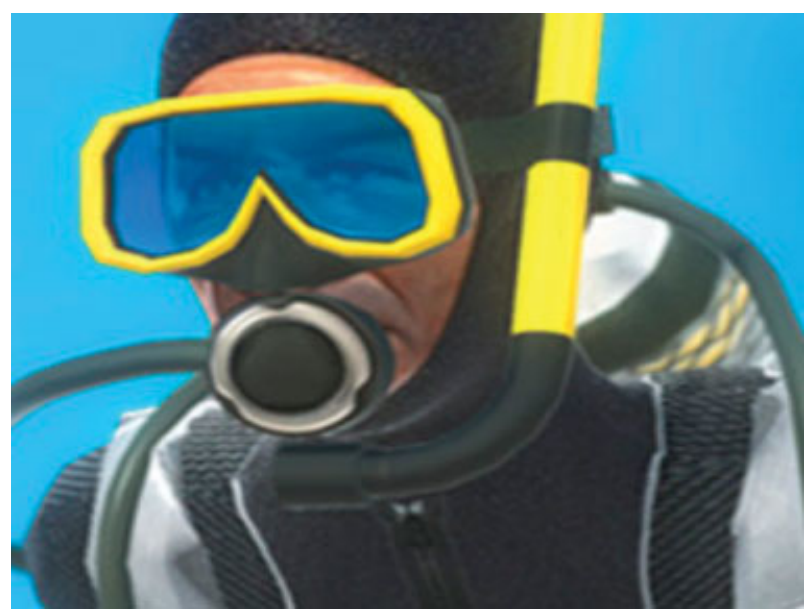

Fig. 2 Buzo marino.

realizó una ecografía FAST. Al momento del estudio tenía colocada una sonda vesical y abundante cantidad de líquido libre en el fondo de saco recto-vesical. En un corte ecográfico transversal a dicho nivel, la acumulación de líquido y la presencia del balón de sonda vesical endoluminal, semejan el equipamiento de un buzo marino. received

August 18, 2017

accepted

September 20, 2017

published online

March 23, 2018
DOI https://doi.org/

10.1055/s-0038-1637030.

ISSN 1852-9992.
Copyright (c) 2019, Sociedad Argentina de Radiología. Publicado por Thieme Revinter Publicações Ltda., Rio de Janeiro, Brazil. Todos los derechos reservados.

\section{License terms}

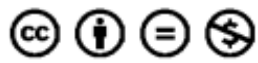

